\title{
HOW SOCIAL MARKETING CAN ADDRESS THE OBESITY ISSUE: THE ROLE OF CORPORATE REPUTATION
}

William Lake, University of Adelaide, Australia

Jodie Conduit, University of Adelaide, Australia

\begin{abstract}
There is an increasing level of government and non-profit organisations holding organisations to account for their social responsibility (Zyglodopoulos, 2002). Such efforts often consist of social marketing campaigns with the ultimate goal to bring about attitudinal and behavioural change in undesirable behaviours such as smoking, gambling, drinking and obesity (Hastings, MacFayden, and Anderson, 2000; Andreasen, 1994). The impact of social marketing can be explained using institutional theory, which draws an association between social norms, the norms of an organisation, and the support of key stakeholder groups. It recognises that an organisation's environment contains social and cultural norms that define social reality (Handelman \& Arnold, 1999; DiMaggio 1988). The purpose of a social marketing campaign is to impact on these societal norms and values (Hastings, MacFayden \& Anderson, 2010). These social norms define the institutional norms which stakeholders expect the organisation to adhere (Handelman \& Arnold, 1999). Maignan \& Ferrell (2004), in proposing a stakeholder view of corporate social responsibility, recognised the need for managerial processes to conform to stakeholder norms. Organisations that conform to social norms provide a show of cultural allegiance with their stakeholders and are to be rewarded for this support (Mohr \& Webb, 2005). Conversely, where social norms shift as a result of a social marketing campaign and they are no longer consistent with the norms of an organisation, customers would be expected to disassociate from the organisation. Where customers are able to draw a connection between the social marketing message and the products or operations of a company, it is feasible to predict a positive influence on the firm's corporate reputation. Bhattacharya \& Elsbach (2002) considered the concept of social marketing and organisational identification and highlighted circumstances where social marketing impacted upon corporate reputation (Bhattacharya \& Elsbach, 2002). This paper further investigates this interplay of social marketing, consumer-based corporate reputation and purchasing intentions. It demonstrates the impact of being exposed to a social marketing campaign on customer perceptions of corporate reputation and their subsequent purchasing intentions.
\end{abstract}

This study utilised an experimental design with respondents exposed to a series of social marketing messages prior to completing a five dimensional customer-based corporate reputation construct (Walsh \& Beatty, 2007) and indicating their purchase intentions. The 'control' survey contained social marketing messages on smoking, drinking and gambling that did not relate to the operations of the commercial organisations investigated. The 'test' surveys contained the same social marketing messages with the addition of social marketing messages pertaining to obesity. These images and messages reflected negatively upon the operations of the organisation (a well-known, global fast food organisation). An online panel was accessed and a sample size of 288 usable respondents (144 for each of the groups).

The results of the group exposed to social marketing were significantly different from the group not exposed to the social marketing with regards to overall corporate reputation. There was a significant difference between the test groups for the corporate reputation dimensions of customer orientation and product and service quality, but not for the financial strength and reliability of the organisation. There was also a significant difference in purchasing intentions for products between the test and control groups, with the exposure to social marketing having a negative impact upon purchasing intentions of consumers.

The findings of this research provide some support for social marketing campaigns as an avenue for governments and notfor-profit organisations to facilitate change in consumer perceptions. It furthers the idea that social marketing can impact corporate reputation and purchasing intentions. These findings support the continued use of social marketing campaigns to impact on product-related anti-social behaviour such as cigarettes, fast food and alcohol. Interestingly, this could give rise to a self-fulfilling prophecy. As organisations recognise the impact that social marketing campaigns can potentially have on the attitudes of their consumer groups, they will be inclined to devote more resources to their corporate social performance.

References available upon request 